\title{
Anti-retroviral strategies for AIDS and related diseases
}

Mark A Wainberg, PhD, Andre Dascal, MD, Jack Mendelson, MD

\begin{abstract}
ma Wainberg, A Dascal, J Mendelson. Anti-retroviral strategies for aIDS and related diseases. Can $J$ Infect Dis 1991;2(3):121-128. The replication cycle of human immunodeficiency virus type 1 (HIV-1) and other retroviruses consists of four stages: attachment of the virus to specific receptors on the cell surface; uncoating of the viral nucleic acid and conversion to DNA; production of viral RNA and proteins; and assembly and liberation of progeny virus from the cell. Each of these steps represents a potential target for antiviral chemotherapy. Combinations of drugs which act against different steps in the viral replication cycle might be expected to have synergistic potential. Zidovudine (AZT) is the most widely used drug to date for impeding the replication of HIV-1. Although AZT therapy has been reasonably successful, it has not been free from toxicity. In addition, there have been several reports of isolation of AZT-resistant variants of HIV-1.
\end{abstract}

Key Words: AIDS, HIV-1, Therapy, Viral replication, Zidovudine

\section{Stratégies anti-rétrovirales dans le syndrome d'immunodéficience acquise (SIDA) et les maladies apparentées}

RESUME: Le cycle de réplication du virus d'immunodéficience humaine de type 1 (VIH 1) et des autres rétrovirus s'effectue en quatre stades: le virus se fixe aux récepteurs spécifiques présents à la surface de la cellule; il contient une enzyme appelée transcriptase inverse qui transcrit l'acide nucléique viral en ADN; il y a production d'ARN viral et de protéines, puis les gènes viraux intégrés sont dupliqués avec les gènes cellulaires normaux. Chacune de ces étapes représente une cible potentielle pour la chimiothérapie antivirale. L'association de médicaments qui agissent à divers stades de la réplication virale pourrait avoir un potentiel synergique. La zidovudine (AZT) est le médicament le plus utilisé jusqu'à ce jour pour bloquer la réplication du VIH 1. Bien que l'efficacité du traitement par l'AZT ait été raisonnablement démontrée, il n’est cependant pas exempt de toxicité. De plus, plusieurs rapports rapportent l'isolement de variantes du VIH 1 résistantes à l'AZT.

Sir Mortimer B Davis - Jewish General Hospital and McGill AIDS Centre, McGill University, Montreal, Quebec

Correspondence and reprints: Dr Mark A Wainberg, Sir Mortimer B Davis - Jewish General Hospital, 3755 Cote Ste-Catherine Road, Montreal, Quebec H3T 1E2. Telephone (514) 340-8260, Fax (514) 340-7502

Received for publication September 4, 1990. Accepted January 12, 1991 
$I^{2}$ RECENT YEARS, THE NEED FOR EFFECTIVE retroviral chemotherapy has become apparent, largely due to the discovery of three important human retroviruses, each of which plays an important role in human disease. The first of the viruses identified was the human $T$ cell lymphotropic virus type 1 (HTLV-1), known to be the etiological agent of adult T cell leukemia (1).

This disease is most prevalent in parts of southeastern Japan, Africa and the Caribbean. However, it is as yet uncommon in Europe and North America. The other two human retroviruses of note are the human immunodeficiency viruses types 1 and 2 (HIV-1 and HIV-2), the causes of the acquired immune deficiency syndrome (AIDS). HIV - 1 was first isolated in 1983 and 1984 (2,3); it is responsible for the vast majority of AIDS in the world. Seroepidemiological evidence suggests that this virus first originated in the countries of East and Central Africa, from which it spread to other areas and continents. In contrast, HIV-2 seems thus far to be localized to parts of West Africa (4), although some cases in Europe and North America have been described. In general, HIV-1 is a much more virulent agent than HIV-2; it appears to spread far more easily than HIV-2 and is also more likely to cause serious disease in infected individuals $(5,6)$.

In addition to causing AIDS, HIV-1 is also associated with a wide variety of wasting and neurological syndromes, including myelopathy, neuropathy and dementias (7). As increasing knowledge about HIV-1 has been generated in the past decade, scientists have been able to characterize this virus in considerable detail, including a description of the mechanism whereby it infects cells and becomes cytopathic. A significant understanding of the life cycle of HIV-1 and of the nature of the immune response generated against it by infected individuals has been achieved. Knowledge of the viral replication cycle has given rise to a wide variety of therapeutic approaches which are of potential use in therapy of not only HIV-1, but of other human retroviruses as well.

\section{BACKGROUND}

The first discovery that a virus can cause profound suppression of immune responsiveness in infected individuals was made by Von Pirquet (8), who showed that infection by the measles virus can lead to profound dysfunction of the ability of the immune system to recognize antigenic stimuli. He believed that such suppression of immunological reactivity was responsible for the fact that many measles sufferers were prone to pneumonia and other opportunistic infections, from which they frequently died. Since that time, other inves- tigators have shown that immunological dysfunction can also be caused by influenza, cytomegalovirus, Epstein-Barr virus and herpes simplex viruses (9). Thus, AIDS is only the latest in a long series of viral illnesses that result in suppression of immune responsiveness.

This fact notwithstanding, the dysfunction which often occurs following infection by HIV-1 is more severe and less likely to be reversed than that accompanying other sorts of viral illness. Indeed, AIDs patients commonly lose the ability to mount successful immune responses against a wide variety of opportunistic pathogens and neoplasms, leading to disease susceptibility and often death. Since the discovery of HIV-1 in 1983-84 $(2,3)$, a number of laboratories have actively sought to understand the mechanisms whereby this virus replicates in cells and ultimately destroys them. Indeed, it is the ability of HIV-1 to grow selectively in and cause destruction of CD4bearing $\mathrm{T}$ lymphocytes (T4 cells) which results in the collapse of the immune system (10).

In addition, it is important that HIV-1 can replicate in certain other cell types which also play important roles in the immune system. These cells include monocytes and macrophages, as well as endothelial, neural and dendritic cells. HIV-1-infected monocytes are thought to be capable of crossing the blood-brain barrier, and hence are thought to play an important role with regard to the dissemination of HIV-1 to the brain (11). This mechanism is apparently responsible for many of the dementias associated with the neurological consequences of HIV-1 infection and AIDS.

\section{THE LIFE CYCLE OF RETROVIRUSES}

Only an understanding of the viral life cycle will make possible an appreciation of the various events which transpire during the course of viral replication and against which antiviral therapy might be directed. In the case of all retroviruses, the life cycle begins with a specific interaction between the viral envelope and a receptor at the cell surface (Figure 1) (10). In the case of both HIV-1 and HIV-2, but not HTLV-1, the cellular receptor has been identified as the CD4 cell surface antigen (12). This structure is present at high concentrations on helper $\mathrm{T}$ lymphocytes and to lesser extent on macrophages, B cells, endothelial cells and certain types of brain cells. The binding to CD4 takes place through interaction of the receptor with proteins found on the envelope of the virus, called gp 120 and gp4l (Figure 2). Initial binding to $\mathrm{CD} 4$ is mediated by gp 120 ; this binding is followed by binding of gp 41, which helps to propel the virus through the plasma membrane of the cell and into the cytoplasm. Viral entry, in fact, 


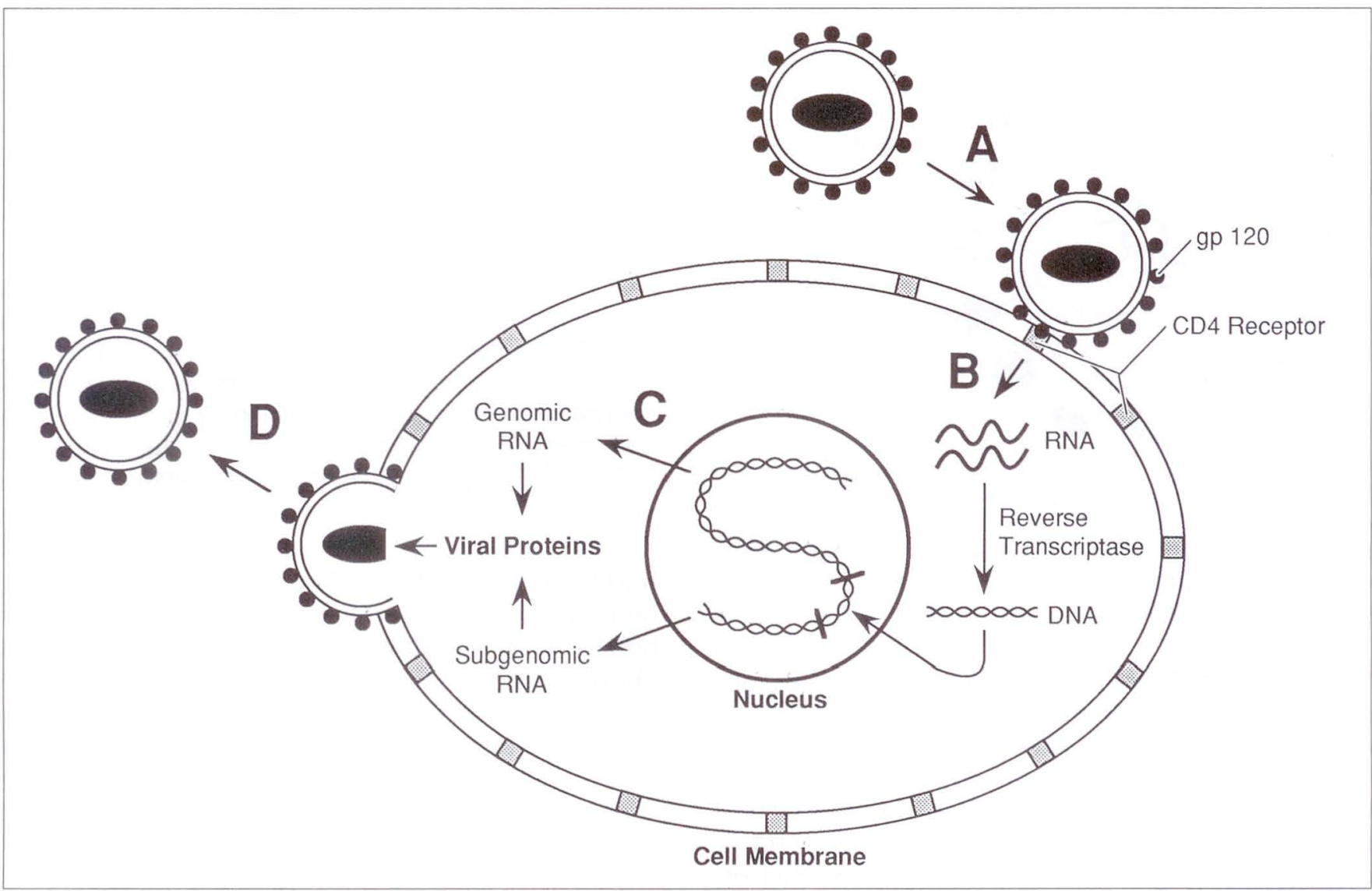

Figure 1) Replication cycle of human immunodeficiency virus type 1 showing binding of virus to specific CD4 receptors at the cell membrane (A); uncoating of viral RNA and its conversion by reverse transcriptase to DNA which integrates into host cell chromosomes (B): production of viral RNA and proteins (C); and assembly and release of progeny viruses from the cell (D)

occurs as a consequence of fusion between the viral envelope and the outer membrane of the cell. An important consequence is that the proteins which surround the viral nucleic acid are digested away. Thus, viral nucleic acid becomes exposed to the cytoplasm of the cell.

The viral genome consists of two pieces of single-stranded RNA. These chains are linked together in a complex with an enzyme known as reverse transcriptase (also called RNA-dependent DNA polymerase). This enzyme is itself a product of the viral genome and has the task of repeatedly copying viral RNA to yield double-stranded DNA which can become incorporated into the genome of the host cell. This double-stranded DNA migrates into the nucleus, where it can integrate into the DNA of a number of host cell chromosomes. Once this happens, the newly integrated DNA is called proviral DNA. It can now be transcribed by host-cell DNA-dependent RNA polymerase to give rise to viral RNA through the usual mechanisms. Thus, the proviral DNA is regarded by the cell as equivalent to its own normal cellular DNA. There is no method yet devised to extract such viral DNA from cells once integration has taken place. The viral mRNA once formed can be translated along ribosomes to give rise to viral proteins. These ultimately assemble with newly made viral RNA at the cell membrane to yield progeny virus particles. The latter are now able to bud out from the cell surface and attach to uninfected cells. Thus, the viral life cycle can begin all over again.

\section{THERAPEUTIC STRATEGIES}

A number of therapeutic strategies are now being used to combat HIV-1 infection, while other approaches are still in the developmental stage (Table 1). These strategies can be divided into two categories: direct antiviral chemotherapy; and immunomodulating agents intended to boost the patient's immune defences against HIV-1 infection. Most retroviral chemotherapy strategies are similar in that they attempt to arrest viral replication at some point in the viral life cycle (Figure 1). However, different drugs act at different stages of viral replication. The variation may be advantageous in that combinations of antiviral agents, each acting at a different site in the viral life cycle, may ultimately have synergistic potential. 


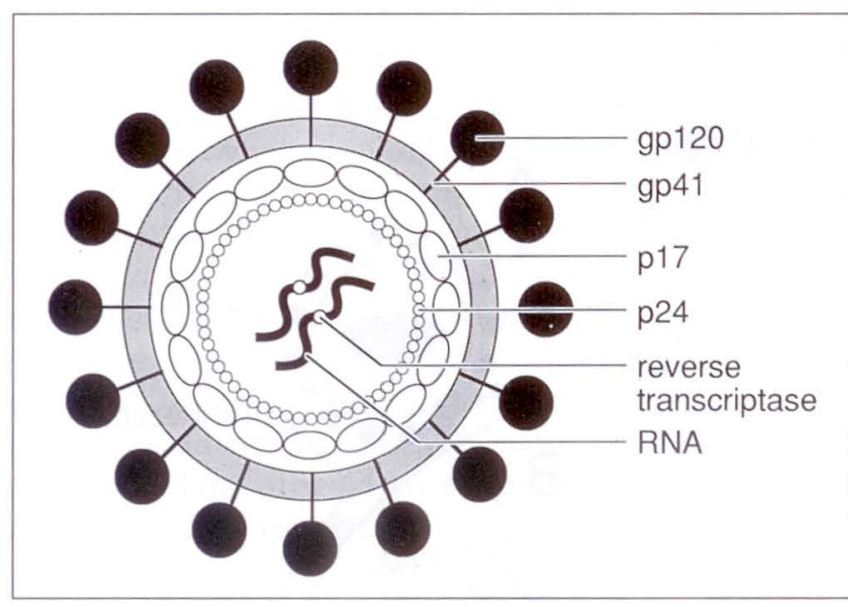

Figure 2) Schematic representation of human immunodeficiency virus type 1 showing the external envelope glycoproteins, gp120 and gp41, surrounding viral RNA and other viral proteins, including the p51/66 reverse transcriptase complex

Virus adsorption and penetration: The initial step at which therapeutic intervention might be contemplated is that of attachment of a retrovirus to a susceptible cell. Because adsorption of HIV-1 takes place as a consequence of interaction between viral gp120, found at the envelope, and a cell surface receptor known as CD4, a number of investigators have attempted to block this interaction (Figure 1) (12). The most successful approach thus far has been based on the use of a soluble form of CD4 produced through genetic recombinant technology (13). The addition of soluble CD4 to HIV-1 has been shown to bind the gp 120 structures at the viral envelope in such a way as to completely inhibit these viruses from attaching to otherwise susceptible cells (14). Soluble CD4 successfully antagonizes the initial event in the virus replication cycle. Cells do not become infected by HIV-1 under conditions of exposure to soluble CD4 and, of course, no progeny virus can be made.

In recent years, a number of groups have tried to modify this strategy by using only the peptide regions of CD4 responsible for binding of HIV-1. The results of early clinical investigations using CD4 and CD4-derived peptides have not yet been published. However, it appears that soluble CD4 is unlikely to be therapeutically effective because it is cleared fairly rapidly through the kidneys after intravenous injection. It is hoped that a variety of truncated CD4 structures, which have now also been expressed through recombinant technology, may not be subject to this problem. One positive aspect of trials to date is that patients treated with $\mathrm{CD} 4$ have not produced auto-antibodies against the CD4 moiety itself. This is an important observation because a major concern
TABLE 1

Targets of retroviral therapy

\begin{tabular}{|c|c|}
\hline Site of drug action & Compound or drug \\
\hline \multirow[t]{2}{*}{ Virus receptor } & Soluble CD4 \\
\hline & Soluble CD4 peptides \\
\hline \multirow[t]{4}{*}{ Reverse transcriptase } & Zidovudine \\
\hline & Dideoxyinosine \\
\hline & Dideoxycytidine \\
\hline & Other dideoxynucleoside analogues \\
\hline \multirow{3}{*}{$\begin{array}{l}\text { Synthesis and process- } \\
\text { ing of viral RNA and } \\
\text { proteins }\end{array}$} & Ribavirin \\
\hline & Antisense RNA \\
\hline & Protease inhibitors \\
\hline \multirow{3}{*}{$\begin{array}{l}\text { Viral budding and/or } \\
\text { expression at the } \\
\text { cell surface }\end{array}$} & Alpha-interferon \\
\hline & Beta-interferon \\
\hline & Other immune activators \\
\hline
\end{tabular}

had been that introduction of soluble CD4 to the body might result in formation of anti-CD4 antibodies and autoimmune disease. Of course, a shortcoming of the CD4 approach, aimed at preventing the interaction of virus with susceptible target cells, is that it will neither eradicate infected cells from the body nor prevent such cells from producing more viruses.

Reverse transcriptase: A second important stage at which to consider intervention strategy is that of viral reverse transcriptase. Indeed, this is probably the most logical target for antiviral therapy, for human cells do not themselves possess this enzyme. Agents which antagonize viral reverse transcriptase activity will successfully prevent the synthesis of viral DNA. The drug that has been most widely used thus far for the therapy of HIV-1 and associated diseases is a competitive inhibitor of reverse transcriptase named zidovudine (3'-azido-3'-deoxythymidine; AZT) (15). This drug is an analogue of thymidine. When it is incorporated into newly made viral DNA in place of thymidine, the formation of viral DNA is arrested. The results of a number of clinical trials have now shown that patients treated with AZT have lived longer than would otherwise be the case $(16,17)$. Furthermore, treatment with AZT may help to delay the onset of AIDS symptoms in HIV1-infected individuals (18). Unfortunately, AZT is not without serious side effects. Although it acts preferentially at the level of viral reverse transcriptase, it seemingly can also be a competitive inhibitor of normal cellular polymerases, a finding which may explain the bone marrow toxicity of this drug (19).

A number of other nucleoside antagonists of viral reverse transcriptase activity have also been synthesized and entered in clinical trials. These include dideoxyinosine and dideoxycytidine. Both of these compounds have yielded important anti- 
HIV activity in both in vitro studies and early phase I-phase II clinical trials (20-22). Both compounds also exhibit problems of toxicity. In addition, it is important to note that a number of non-nucleoside antagonists of viral reverse transcriptase activity have now been described. Several of these compounds appear to be highly specific, acting uniquely against HIV-1 reverse transcriptase while not impairing the reverse transcriptase activities of other retroviruses, including HIV-2 and HTLV-1 $(23,24)$. Another compound with the ability to antagonize viral HIV-1 reverse transcriptase activity is phosphonoformic acid (Foscarnet; Astra Pharmaceuticals) (25). AZT, along with other drugs of the nucleoside family, is primarily effective at preventing the generation of proviral DNA in newly infected cells, and may have no therapeutic value for cells that already possess HIV-1 DNA in their nuclei. Cessation of AZT therapy for reasons of drug toxicity or patient noncompliance has been followed in some instances by enhanced viral replication and isolation of HIV-1 (26). Patients who are helped by AZT and drugs of this class and who tolerate therapy well may have to continue to receive such treatment for the rest of their lives.

Production of viral RNA and proteins: This is the logical next step at which to consider the possibility of anti-retroviral therapy. One drug that has had limited use in this regard is ribavirin, a compound which has already proved useful in the therapy of respiratory syncytial virus illness in children. Ribavirin is thought to antagonize viral protein synthesis, preventing the guanylation of newly made viral mRNA. Ribavirin has been shown to interfere with HIV-1 replication in tissue culture (27). However, clinical trials with this drug have failed to demonstrate a consistent benefit to patients. In addition, ribavirin and AZT are apparently antagonistic with regard to inhibition of HIV-1 replication in tissue culture (28). The basis for this antagonism may be that ribavirin somehow interferes with the phosphorylation of AZT to its active triphosphate form.

Another approach which may be taken in the future is the use of synthetic oligonucleotides. These oligonucleotides might be able to bind to viral mRNA and, accordingly, interfere with the production of viral proteins. This method is called the 'antisense approach', because the nucleotide sequences involved are opposite in sequence to viral mRNA. Similar protocols have been devised to interfere with the expression of a variety of onc genes in cancer cells, hopefully to bring about a nontransformed cellular state (29). Indeed, experimental success with this technology has been achieved with regard to certain types of leukemic cells studied in tissue culture, and HIV replication (30). However, this approach is still in the experimental stage because of problems relating to the delivery of oligonucleotides to infected cells in vivo. This problem is not a trivial consideration. No one has yet devised a mechanism to internalize antisense molecules in a specific fashion in target cells. Although liposomes and other delivery systems are currently being developed towards this end, it is clear that significant progress will require many years of intense work.

Another approach is that of interfering with the addition of certain sugars to viral proteins, which are often able to function biologically only if certain sugar moieties are present. Inhibition of this process, termed 'glycosylation', can be accomplished through compounds such as castanospermine and 1-deoxy-nojirimycin $(31,32)$. Certain of these drugs have already entered phase I clinical trials, the results of which are not yet available. Synergy with compounds that act at other stages of viral replication, eg, AZT, is also an important possibility.

A further strategy of interfering with viral replication is that of blocking the activity of a viral enzyme called 'protease'. The replication strategy of HIV-1 is complex; certain viral proteins are made as hybrids from regions of viral DNA that overlap two separate viral genes. For example, the gag and pol genes encode the viral structural proteins and the reverse transcriptase enzyme, respectively, yet together produce one large protein of molecular weight 160 kilodaltons. This protein is subsequently cleaved by protease to yield the individual reverse transcriptase and the viral structural proteins. Several groups have been able to engineer soluble peptides which can interfere with the function of this protease $(27,33)$. Cells treated with these peptides produced viruses which contained the 160 kilodalton precursor protein rather than the smaller viral proteins normally found. The 160 kilodalton protein is nonfunctional and cannot carry out the reverse transcriptase function normally assigned to a segment of this molecule.

Accordingly, viruses produced by cells treated with protease inhibitors do not contain active reverse transcriptase and are noninfectious for other cells. It is anticipated that phase I clinical trials of the protease inhibitor approach will begin shortly. This strategy is also appealing because of the possibility that protease inhibitors will be used in combination therapy with nucleoside antagonists of reverse transcriptase to achieve a synergistic effect.

Viral budding and immunomodulation: Finally, the virus is assembled at the plasma membrane 
and released into the extracellular space, another stage in the viral life cycle at which effective intervention strategy might be useful. It is important to realize that viral proteins are usually found in abundance at the cell surface when viral assembly takes place. These proteins may serve as antigens for reaction with antiviral antibodies and other effectors of immune responsiveness. Other effectors may include cytotoxic T lymphocytes, natural killer cells, and cells which participate in antibodymediated cellular cytotoxicity reactions (34). Of course, all individuals infected with HIV-1 will eventually mount immune responses against this virus. Indeed, it is on this basis that blood is screened and individuals who are HIV seropositive and who presumably harbour infectious virus in their circulation are excluded as donors. Unfortunately, such antiviral immunity, while present, does not succeed in controlling viral infection in a high proportion of individuals. It is worth considering, therefore, whether the use of immunomodulators might serve to strengthen the efficiency of anti-HIV immunity in infected individuals.

Indeed, a number of therapeutic agents with the ability to strengthen immune responsiveness have already entered clinical trials. These include alpha- and beta-interferon, granulocyte-macrophage colony-stimulating factor and human granulocyte colony-stimulating factor. The latter two proteins are growth factors which may increase patient tolerance for AZT and other drugs with apparent bone marrow toxicity. One possible caveat is that these growth factors may activate HIV replication in latently infected cells.

It should also be noted that interferons may help to prevent previously uninfected cells from being infected by HIV-1. Several studies have shown that treatment of HIV-1-infected lymphocytes with recombinant alpha-interferon led to an accumulation of defective viruses in the cytoplasm without decreasing cell viability. It should be noted, as well, that agents to potentiate antiviral immune responsiveness may logically be used in concert with protease inhibitors and/or nucleoside inhibitors of reverse transcriptase, to yield potentially synergistic effects. In fact, it is not unlikely that combinations of viral chemotherapeutic agents and immune modulators may ultimately be successful in the therapy of HIVassociated disease.

One of the consequences of the synthesis and budding of newly formed HIV-1 from the plasma membrane in tissue culture is the generation of multinucleated cells. The formation of such cells apparently results from interactions between CD4 molecules at the surface of uninfected lympho- cytes with viral gp 120 at the surface of an infected cell (35). Hence, the formation of giant cells may be due to recruitment of hitherto uninfected lymphocytes to fuse with cells already infected with HIV-1. The instability of these giant cells is thought by some to constitute an important mechanism whereby HIV-1 manifests its cytopathic effects. However, this theory is controversial, since multinucleated cells have not been detected with any frequency in the circulation of HIV-infected individuals. In any case, nucleoside antagonists of viral reverse transcriptase protease inhibitors and/or modulators of antiviral immunity may all contribute to a lessening of virus-induced cytopathic effects as well as to decreased levels of viral replication.

\section{DRUG RESISTANCE}

A potential complication of AZT therapy is the development of strains of drug-resistant viruses in patients who have received this nucleoside for longer than 27 to 36 weeks $(36,37)$. It must be emphasized that HIV drug resistance is for now an in vitro observation without clinical correlates. Nonetheless, it is clear that this development is grounds for concern. Efforts are now underway to assess whether patients infected with drug-resistant variants of HIV-1 are more prone to develop AIDS than patients without such variants. Current attempts are designed to assess whether drugresistant strains of HIV-1 are as virulent as wildtype strains, and whether AZT-resistant viruses may be sexually transmitted.

It is likely that AZT resistance results from mutations within the pol region of the HIV-1 genome. This region is known to encode viral reverse transcriptase. Accordingly, changes within this region of the viral genome may give rise to altered forms of reverse transcriptase with differential sensitivities to AZT. For this reason, it is important to develop other nucleosides to impede the replication of HIV-1. Towards this end, a number of compounds have been synthesized and have already entered clinical trials. Among these are dideoxycytidine and dideoxyinosine, as well as other more novel structures also designed to act at the level of the viral reverse transcriptase.

One group of researchers has successfully identified a series of four mutations within the polymerase gene of HIV-1 which account for subtle amino acid changes in the reverse transcriptase molecule of AZT-resistant strains (38). Furthermore, it appears that ongoing mutations under conditions of AZT pressure may give rise to more highly mutated strains which are increasingly resistant to AZT. It has also been possible to use polymerase chain reaction technology to identify 
sequences corresponding to those which seemingly account for drug resistance in patients infected with AZT-resistant strains of HIV-1 (39). It is hoped that the likely emergence of drug-resistant strains of HIV-1 will eventually be identified on the basis of polymerase chain reaction analysis, prior to the biological outgrowth of such strains. This finding is an important development which may set the stage for changes in treatment modalities, based on detection of variant HIV-1 nucleic acid sequences. Of course, such an eventuality will depend on indications that patients who harbour AZT-resistant strains of HIV-1 are more likely to suffer AZT treatment failure and to progress to more serious disease.

It should be recognized that mutations may also take place in other HIV-1 genes and may give rise to strains resistant to future therapeutic strategies. For example, mutations within the polymerase gene may also yield strains of HIV-1 resistant to protease inhibitors. Mutations within the env gene could potentially give rise to variants of HIV-1 that cannot be blocked effectively by soluble CD4. Researchers must be cognizant of these and other possibilities as therapeutic strategies to combat HIV-1 infection continue to evolve in the years ahead.

\section{CONCLUSIONS}

A number of successful antiviral strategies have been developed which prevent the formation of

\section{REFERENCES}

1. Poiesz BJ, Ruscetti FW, Gazdar AF, et al. Detection and isolation of type $\mathrm{C}$ retrovirus particles from fresh and cultured lymphocytes of a patient with cutaneous T-cell lymphoma. Proc Natl Acad Sci USA 1980;77:7415-9.

2. Barré-Sinoussi F, Chermann JC, Rey F, et al. Isolation of a T-lymphotropic retrovirus from a patient at risk for acquired immune deficiency syndrome (AIDS). Science 1983;220:868-71.

3. Gallo RC, Salahuddin SZ, Popovic M, et al. Frequent detection and isolation of cytopathic retroviruses (HTLV-III) from patients with AIDS and at risk for AIDS. Science 1984:224:500-3.

4. Anderson RM, May RM. Epidemiological parameters of HIV transmission. Nature 1988;333:514-9.

5. De Cock KM, Porter A, Kouadio J, et al. Rapid and specific diagnosis of HIV-1 and HIV-2 infections: An evaluation of testing strategies. AIDS 1990;4:875-8

6. Nixon DF, Huet S, Rothbard J, et al. An HIV-1 and HIV-2 cross-reactive cytotoxic T-cell epitope. AIDS 1990;4:841-5.

7. Aronow HA, Brew BJ, Price RW. The management of the neurological complications of HIV infection and AIDS. AIDS 1988;2:S151-9.

8. Von Pirquet C. Das Verhalten der Kutanen Tuberculin - Reaktion während der Masern. Dtsch Med Wochenschr 1908;34:1297-310. fully infectious viruses at the surface of infected cells. These strategies all interfere with some aspect of the viral cycle, and involve an attack against any one of a number of steps in viral replication. These include: the binding of HIV- 1 to specific receptors at the surface of susceptible cells; the conversion of viral RNA to DNA which can then be integrated into host cell chromosomes and as genetic material for the formation of new viruses; the production of viral RNA and proteins; and the budding of newly made viruses from the host cell's plasma membrane. The most successful drug used thus far for the treatment of patients with HIV- 1 infection is AZT. Although other drugs have also entered clinical trials, it is too early to state whether they will result in better clinical outcomes than those obtained thus far with AZT. It is clear that AZT therapy has prolonged the lives of many people with AIDS, and has retarded the onset of AIDS-like symptoms in many asymptomatic individuals seropositive for HIV-1. Many clinical scientists now believe that the long term management of HIV-1-infected individuals will come to resemble the maintenance of patients suffering from other chronic conditions such as diabetes, hypertension and some of the more treatable neoplasms. This progress will be further enhanced through the advent of combination therapy strategies already under investigation, which will provide the basis for even greater advances in the next decade.

9. Wainberg MA, Mills EL. Mechanisms of virusinduced immune suppression. Can Med Assoc J 1985; 132:1261-5.

10. Maddon PJ, Dalgleish AG, McDougal JS, et al. The T4 gene encodes the AIDS virus receptor and is expressed in the immune system and the brain. Cell 1986;47:333-48.

11. Price RW, Brew B, Sidtis J, et al. The brain in AIDS: Central nervous system HIV-1 infection and AIDS dementia complex. Science 1988;239:586-93.

12. Matthews TJ, Weinhold KJ, Lyerly HK, et al. Interaction between the human $\mathrm{T}$-cell lymphotropic virus type IIIB envelope glycoprotein gp120 and the surface antigen CD4: Role of carbohydrate in binding and cell fusion. Proc Natl Acad Sci USA 1987;84:5424-8.

13. Deen KC, McDougal JS, Inacker R, et al. Soluble CD4 form of CD4 (T4) protein inhibits AIDS virus infection. Nature 1988;331:82-4.

14. Trunecker JA, Luke W, Karjaleinen K. Soluble CD4 molecules neutralize human immunodeficiency virus type 1 . Nature 1988;331:84-6.

15. Furman PA, Fyfe JA, St Clair MH, et al. Phosphorylation of $3^{\prime}$-azido-3'-deoxythymidine and selective interaction of the $5^{\prime}$-triphosphate with HIV reverse transcriptase. Proc Natl Acad Sci USA 1986;83:8333-7.

16. Fischl MA, Richman DD, Grieco MH, et al. The efficacy of azidothymidine (AZT) in the treatment 
of patients with AIDS and AIDS-related complex. N Engl J Med 1987;317:185-91.

17. Fischl MA, Richman DD, Causey DM, et al. Prolonged zidovudine therapy in patients with AIDS and advanced AIDS-related complex. JAMA 1989;262:2405-10.

18. Spector SA, Kennedy C, McCutchan JA, et al. The antiviral effect of zidovudine and ribavirin in clinical trials and the use of p24 antigen levels as a virologic marker. J Infect Dis 1989;159:822-8.

19. Yarchoan R, Broueps P, Spitzer AR, et al. Response of human immunodeficiency virus-associated neurological disease to 3'-azido-3'-deoxythymidine. Lancet 1987;i:132-5.

20. Meng T-C, Fischl MA, Richman DD. AIDS Clinical Trials Group, phase I/II study of combination 2 '-3'-dideoxycytidine and zidovudine in patients with acquired immunodeficiency syndrome (AIDS) and advanced AIDS-related complex. Am J Med 1990;88(Suppl 5B):27S-30S

21. Bozzette SA, Richman DD. Salvage therapy for zidovudine-intolerant HIV-infected patients with alternating and intermittent regimens of zidovudine and dideoxycytidine. Am J Med 1990;88(Suppl 5B):24S-6S.

22. Skowron G, Merigan TC. Alternating and intermittent regimens of zidovudine (3'-azido-3'-deoxythymidine) and dideoxycytidine $\left(2^{\prime}, 3^{\prime}\right.$-dideoxycytidine $)$ in the treatment of patients with acquired immunodeficiency syndrome (AIDS) and AIDS-related complex. Am J Med 1990:88(Suppl 5B):30S-23S.

23. Pauwels R, Andries K, Desmyter J, et al. Potent and selective inhibition of HIV-1 replication in vitro by a novel series of TIBO derivatives. Nature (Lond) 1990;343:470-4.

24. Nakashima H, Balzarini J, Pauwls R, et al. Anti-HIV-1 activity of antiviral compounds, as quantitated by a focal immunoassay in CD4-HeLa cells and a plaque assay in MT-4 cells. J Virol Methods 1990;29:197-208.

25. Sandstrom EC, Byington RE, Kaplan JC, et al. Inhibition of HTLV-III in vitro by phosphonoformate. Lancet 1985;i: 1480-2.

26. Wainberg MA, Falutz J, Fanning M, et al. Cessation of zidovudine therapy may lead to increased replication of HIV-1. JAMA 1989;261:865-6.

27. Haseltine WA. Development of antiviral drugs for the treatment of AIDS: Strategies and prospects. J AIDS 1989;2:311-9.
28. Vogt MW, Hartshorn KL, Furman PA, et al. Ribavirin antagonizes the effect of azidothymidine on HIV replication. Science 1987;235:1376-9.

29. Holt JT, Redner RL, Nienhuis AW. An oligomer complementary to c-myc MRNA inhibits proliferation of HL-60 promonocytic cells and induces differentiation. Mol Cell Biol 1988;8:963-73.

30. Zamecnik PC, Goodchild J, Taguchi Y, Sarin PS. Inhibition of replication and expression of human T-cell lymphotropic virus type III in cultured cells by exogenous synthetic oligonucleotides complementary to viral RNA. Proc Natl Acad Sci USA 1986;83:4143-6.

31. Gruters RA, Neefjes JJ, Tersmette M, et al. Interference with HIV-induced syncytium formation and viral infectivity by inhibitors of trimming glucosidase. Nature 1987;330:74-7.

32. Walker BD, Kowalski M, Goh WC, et al. Inhibition of human immunodeficiency virus syncytium formation and virus replication by castanospermine. Proc Natl Acad Sci USA 1987;84:8120-4.

33. Dreyer GB, Metcalf BW, Tomaszek TA Jr, et al Inhibition of human immunodeficiency virus 1 protease in vitro: Rational design of substrate analogue inhibitors. Proc Natl Acad Sci USA 1989;86:9752-6.

34. Walker BD, Chakrabarti S, Moss B, et al. HIV-specific cytotoxic T lymphocytes in seropositive individuals. Nature 1987;328:345-8.

35. Lifson JD, Reyes GR, McGrath MS, et al. AIDS retrovirus induced cytopathology: Giant cell formation and involvement of CD4 antigen. Science 1986;232:1123-7.

36. Larder BA, Darby G, Richman DD. HIV with reduced sensitivity to zidovudine $(A Z T)$ isolated during prolonged therapy. Science 1989;243:1731-4.

37. Rooke P, Tremblay M, Soudeyns H, et al. Isolation of drug-resistant variants of HIV-1 from patients on long-term zidovudine therapy. AIDS 1989;3:411-5.

38. Larder BA, Kemp SD. Multiple mutations in HIV-1 reverse transcriptase confer high-level resistance to zidovudine (AZT). Science 1989;246:1155-8.

39. Boucher CAB, Tersmette M, Lange JMA, et al. Zidovudine sensitivity of human immunodeficiency viruses from high-risk, symptom-free individuals during therapy. Lancet 1990;ii:585-90. 


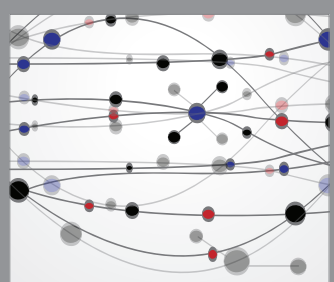

The Scientific World Journal
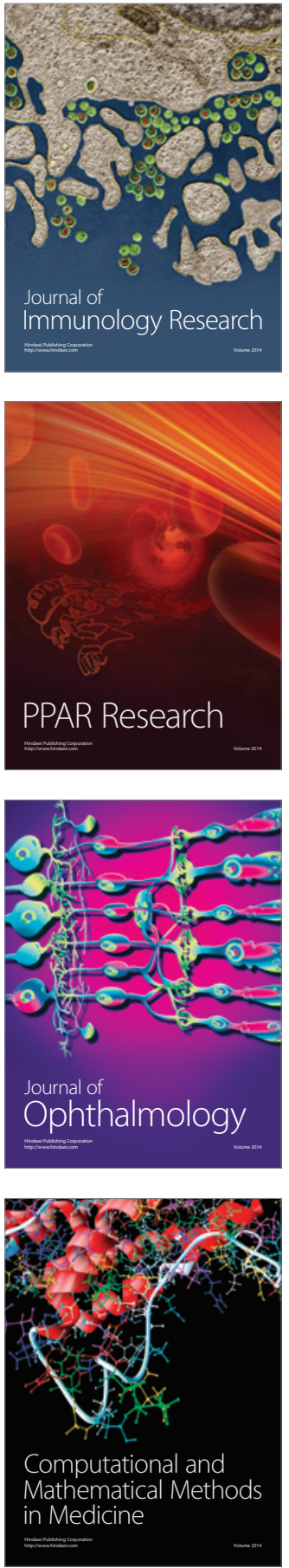

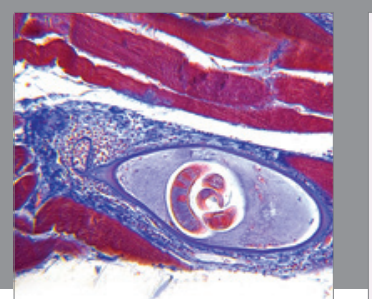

Gastroenterology Research and Practice

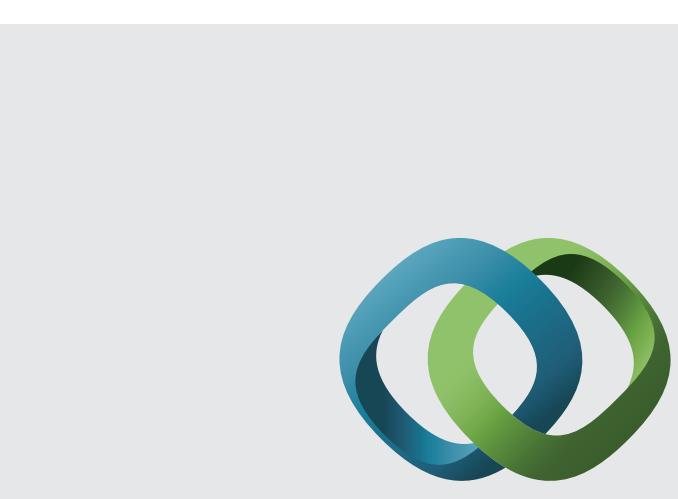

\section{Hindawi}

Submit your manuscripts at

http://www.hindawi.com
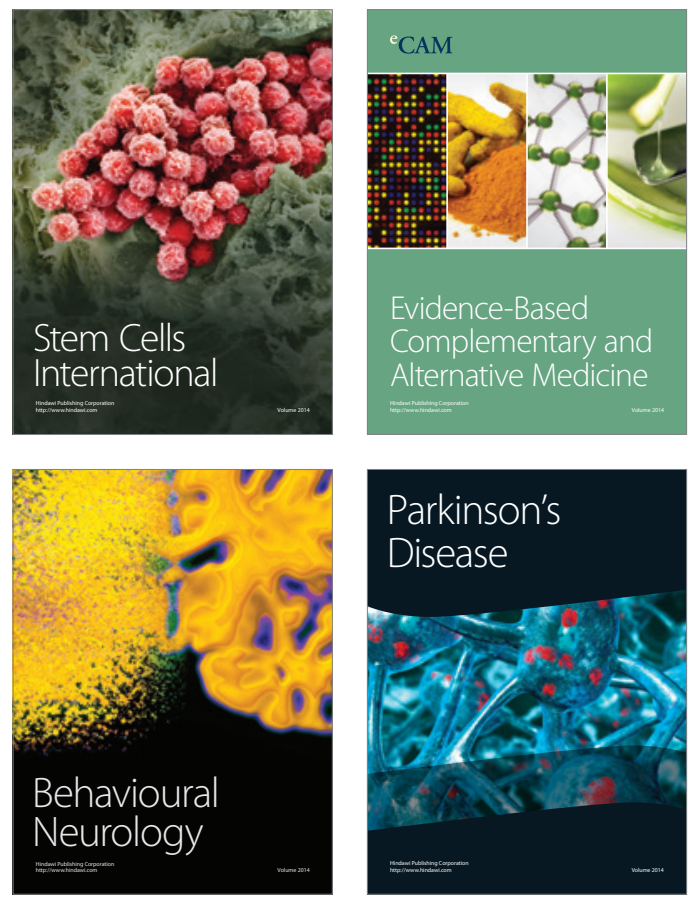
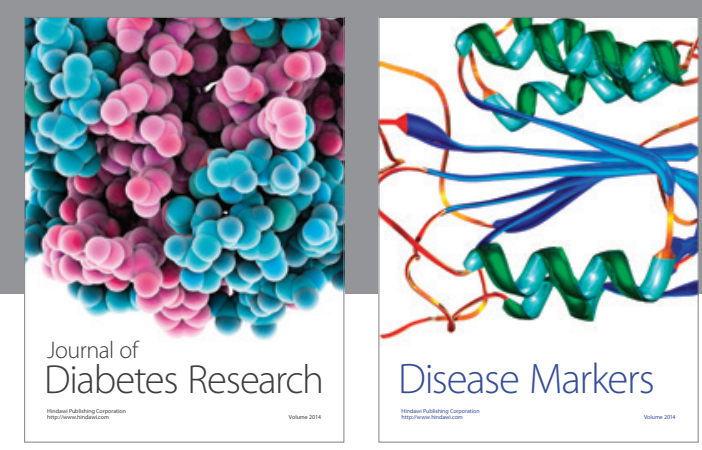

Disease Markers
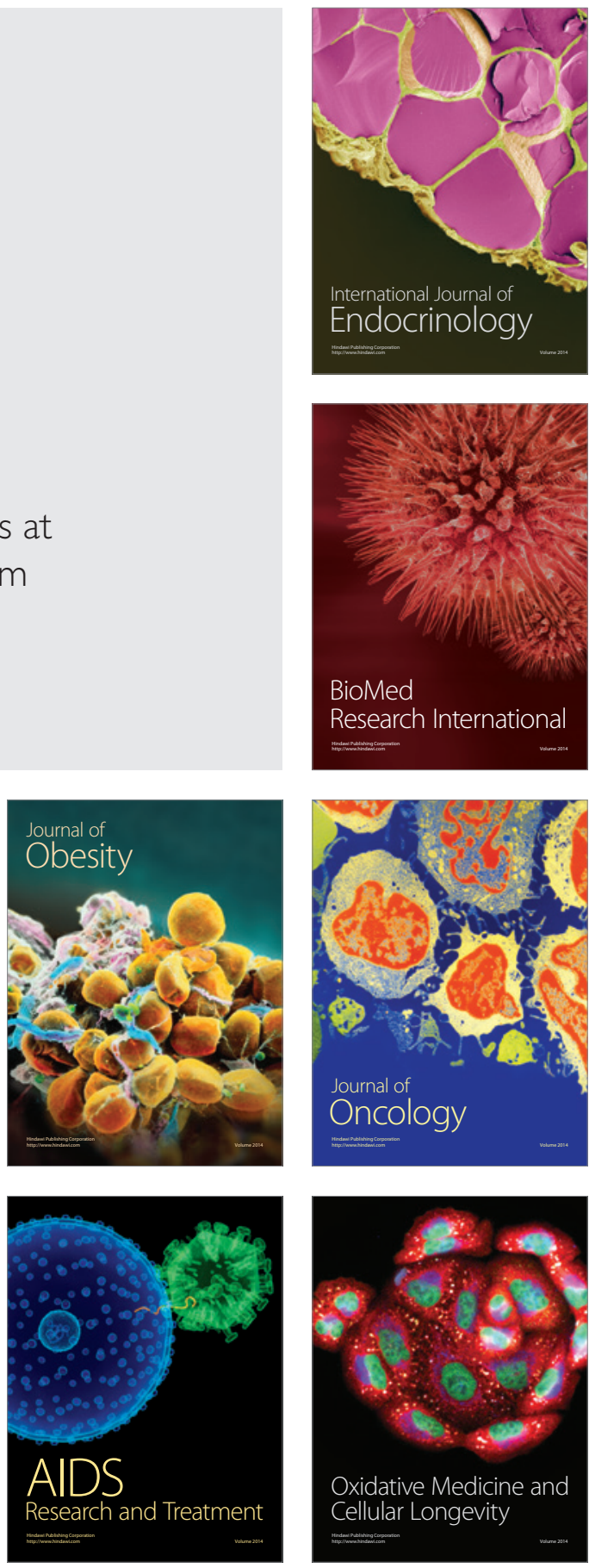